\title{
COVID-19 anosmia and gustatory symptoms as a prognosis factor: a subanalysis of the HOPE COVID-19 (Health Outcome Predictive Evaluation for COVID-19) registry
}

\author{
Jesús Porta-Etessam ${ }^{1,23,24}$ • I Iván J. Núñez-Gil · Nuria González García ${ }^{1,24}$. Cristina Fernandez-Perez ${ }^{2}$. \\ María C. Viana-Llamas ${ }^{3} \cdot$ Charbel Maroun Eid $^{4} \cdot$ Rodolfo Romero $^{5} \cdot$ María Molina $^{6} \cdot$ Aitor Uribarri $^{7}$. \\ Victor Manuel Becerra-Muñoz ${ }^{8}$ - Marcos García Aguado ${ }^{9}$ Jia Huang ${ }^{10}$. Elisa Rondano ${ }^{11}$. Enrico Cerrato ${ }^{12}$. \\ Emilio Alfonso ${ }^{13}$. Alex Fernando Castro Mejía ${ }^{14}$. Francisco Marin ${ }^{15}$. Sergio Raposeiras Roubin ${ }^{16}$. Martino Pepe ${ }^{17}$. \\ Gisela Feltes $^{18} \cdot$ Paloma Maté $^{19} \cdot$ Bernardo Cortese $^{20} \cdot$ Luis Buzón $^{21} \cdot$ Jorge Játiva Mendez $^{22} \cdot$ Vicente Estrada $^{1}$
}

Received: 30 November 2020 / Accepted: 8 February 2021 / Published online: 1 March 2021

(c) Springer-Verlag GmbH, DE part of Springer Nature 2021

\begin{abstract}
Olfactory and gustatory dysfunctions (OGD) are a frequent symptom of coronavirus disease 2019 (COVID-19). It has been proposed that the neuroinvasive potential of the novel SARS-CoV-2 could be due to olfactory bulb invasion, conversely studies suggest it could be a good prognostic factor. The aim of the current study was to investigate the prognosis value of OGD in COVID-19. These symptoms were recorded on admission from a cohort study of 5868 patients with confirmed or highly suspected COVID-19 infection included in the multicenter international HOPE Registry (NCT04334291). There was statistical relation in multivariate analysis for OGD in gender, more frequent in female $12.41 \% \mathrm{vs} 8.67 \%$ in male, related to age, more frequent under 65 years, presence of hypertension, dyslipidemia, diabetes, smoke, renal insufficiency, lung, heart, cancer and neurological disease. We did not find statistical differences in pregnant $(p=0.505)$, patient suffering cognitive $(p=0.484)$, liver $(p=0.1)$ or immune disease $(p=0.32)$. There was inverse relation (protective) between OGD and prone positioning $(0.005)$ and death $(<0.0001)$, but no with ICU $(0.165)$ or mechanical ventilation $(0.292)$. On univariable logistic regression, OGD was found to be inversely related to death in COVID-19 patients. The odds ratio was $0.26(0.15-0.44)$ $(p<0.001)$ and $Z$ was -5.05 . The presence of anosmia is fundamental in the diagnosis of SARS.CoV-2 infection, but also could be important in classifying patients and in therapeutic decisions. Even more knowing that it is an early symptom of the disease. Knowing that other situations as being Afro-American or Latino-American, hypertension, renal insufficiency, or increase of C-reactive protein (CRP) imply a worse prognosis we can make a clinical score to estimate the vital prognosis of the patient. The exact pathogenesis of SARS-CoV-2 that causes olfactory and gustative disorders remains unknown but seems related to the prognosis. This point is fundamental, insomuch as could be a plausible way to find a treatment.
\end{abstract}

Keywords SARS-COV-2 $\cdot$ Anosmia $\cdot$ Prognosis $\cdot$ Hospital $\cdot$ Pathophysiology $\cdot$ COVID-19

\begin{tabular}{|c|c|}
\hline \multicolumn{2}{|l|}{ Abbreviations } \\
\hline CNS & Central nervous system \\
\hline CSF & Cerebrospinal fluid \\
\hline COVID-19 & Coronavirus disease 2019 \\
\hline CRP & C-reactive protein) \\
\hline HOPE-COVID-19 & $\begin{array}{l}\text { Health outcome predictive evaluation } \\
\text { for COVID-19 }\end{array}$ \\
\hline OR & Odds ratios \\
\hline
\end{tabular}

Jesús Porta-Etessam jporta@yahoo.com

Extended author information available on the last page of the article
OGD Olfactory and gustatory dysfunctions OSN Olfactory sensory neurons SARS-CoV-2 Severe acute respiratory syndrome coronavirus 2

\section{Introduction}

Coronavirus disease 2019 (COVID-19) is a multiorgan manifestation caused by a betacoronavirus, the severe acute respiratory syndrome coronavirus 2 (SARS-CoV-2) [1]. Most of patients are asymptomatic or experience mild disease. Depending on the series, between 5 and $10 \%$ progresses to 
more severe disease [2]. Anosmia is a frequent symptom of SARS-CoV-2 infection and could be more frequent in the youngest [3]. Besides is more frequent in SARS-CoV-2 infection than in other viral infections as influenza [3]. Anosmia and ageusia have recently been hinted as significant early symptoms in COVID-19 and could be an isolated symptom with all the epidemiological implications that it entails $[4,5]$. For example, recommend the isolation of patients, as has been suggested by various scientific societies [3, 4].

The pathophysiology of anosmia could be related to patient's prognosis. Although the exact pathogenesis of anosmia in COVID-19 remains unclear, should be related to involvement of nasal epithelium or the olfactory nerves [4]. Moreover, it could be related to the neuroinvasive capacity of the SARS-CoV-2 and explain some of the recent MRI and autopsy findings [6-8]. On the other hand, some studies suggest that could be a marker of early detection and recognition of infected patients $[9,10]$. Hypothesis as the early activations of the immunity as a protector factor could explain anosmia as a good prognosis factor.

The current study aimed to investigate if olfactory and gustatory dysfunction (OGD) in COVID-19 is a good prognosis symptom and analyze the biological plausibility.

\section{Patient and methods}

\section{Study design and population}

Olfactive disorder was recorded on admission from a cohort study of 5868 patients with confirmed or highly suspected COVID-19 infection included in the multicenter international HOPE Registry (https://www.hopeprojectmd.com), The OGD was self-reported. Registry NCT04334291 on ClinicalTrials.gov. The HOPE Registry was established through an international consortium. Detailed information about participating countries and hospitals, protocol and definitions are reported on the website of the Registry. In this interim analysis, hospital data and patients were included until the second of April 2020. All patients discharged (deceased or alive) from any hospital center with a confirmed diagnosis or a COVID-19 high suspicion were included in the HOPE Registry. The local ethics committee approved this study and was consistent with the guidelines of Helsinki. A list of participating hospitals, investigators, collaborators and the protocol is available in the appendix.

\section{Outcome definition}

We assessed the risk of death of patients with OGD on admission of 5868 patients with COVID-19. Patients were stratified into two groups: if absence of olfactive dysfunction, anosmia and hyposmia and dysgeusia.

Characteristics of olfactory alterations, defined as anosmia (complete absence of olfaction), hyposmia (reduced olfaction, with at least two types of smell preserved), dysosmia (reduced olfaction with presence of unpleasant smells), and other (including difficult to define sensations) and gustatory alterations, defined as defined as ageusia (complete absence of taste), hypogeusia (reduced taste,), dysgeusia (reduced and unpleasant taste), and other.

Primary endpoint was defined as all-cause in-hospital death. Secondary outcomes were in-hospital complications such respiratory insufficiency, acute kidney injury, pneumonia, sepsis and embolic events.

All patients where asked about OGD in admission when certain data are not available because afasia, or nnconscious or confused patients or those who were not able to complete the study protocol were excluded

\section{Statistical analysis}

Data are presented as mean \pm standard deviation for continuous variables with a normal distribution, median (interquartile range) for continuous variables with a non-normal distribution, and as frequency (\%) for categorical variables. Student's $t$ test and the Mann-Whitney $U$ test were used to compare continuous variables with normal and non-normal distributions, when needed. The Chi-squared test or Fisher's exact test was used to compare categorical variables. Univariate analysis was performed for qualitative variables and reported as odds ratios (OR) with $95 \%$ CI. Given the multiplicity of variables, only factors with $p<0.01$ on univariate analysis (dyslipidemia, diabetes mellitus, smoking, chronic kidney failure, heart disease, lung disease, cerebrovascular disease, connective disease, cancer, immunosuppression condition were entered into the Cox multivariate regression analysis to define independent risk factors for the main outcome. Possible collinearity and interactions were evaluated with the introduction of multiplicative terms calculating the tolerance and the variance inflation factor. The relationship between olfactive disorders and the predicted probability of death was graphically represented after modeling this association using fractional polynomials. All tests were two-sided, and a $P$ value less than 0.05 was considered statistically significant. Statistical analysis was performed with the IBM SPSS 20.0 software package and STATA software, version 15 .

\section{Study protocol}

The HOPE-COVID-19 (Health Outcome Predictive Evaluation for COVID-19) is an international "real-world" all-comers retrospective cohort registry from all patients 
discharged (deceased or alive) after hospital admission for SARS-CoV-2 infection. It was performed as an initiative without conflict of interest, with voluntary participation and no financial remuneration. The study was approved by Ethics Research Committee from the Hospital Clínico San Carlos (Madrid, Spain) (20/241-E) and the Spanish Agency for Medicines and Health Products classification (EPA-0D). It was also performed according to the ethical principles of the Declaration of Helsinki and Good Clinical Practice Guidelines. The study was registered 157 online at ClinicalTrials.gov (NCT04334291). Written informed consent was not requested due to the anonymized nature of the study and the situation of alarm in health resources due to the pandemic. The only exclusion criterion was the patient's refusal to participate. The list of participating hospitals and investigators, as well as study protocol and the Research Ethics Committee approval are available online (https://hopep rojectmd.com). Each participant center filled in an online anonymized database, available on the same website. All the authors reviewed the manuscript and vouch for the accuracy and completeness of the data provided.

\section{Results}

\section{Clinical characteristics}

From 5868 patients, there were 469 that were not included because of lack of clinical data. Mean age was $64.27 \pm 16.93$. 59.2\% (2906) were male. 84.5\% (4152) were Caucasian, 11.5\% (563) Latino-American, 2.7\% (133) Asian and 0.6\% [29] Afro-American. There were 19 (9.4\%) of pregnant patients. There were $5.2 \%$ (230) smokers $49.5 \%$ (2423) hypertension, 34.1\% (1666) with dyslipidemia, 19.4\% (952) suffer diabetes, 6.7\% (329) renal insufficiency, 13.3\% (947) lung disease, $23.6 \%$ (1148) heart disease, $8.2 \%$ (395) neurological diseases, $2.7 \%$ (131) connective tissue disease, $3.9 \%$ (189) liver disorder, $13.8 \%$ (667) cancer and 7.5\% (344) immune disease (Table 1). The percentage of anosmia or hyposmia was 6.4\% (377), dysgeusia 6.9\% (404) and any $8.5 \%$ (505) (Table 2). Of total of patients, 6.02\% (303 were admitted in ICU, 7.2\% (346) needed mechanical ventilation, $10.40 \%$ (495) required to adopt the prone position and $22.00 \%$ (1079) were death (Table 2).

There was statistical relation in multivariate analysis for OGD in gender, more frequent in female $12.41 \%$ vs $8.67 \%$ in male, related with age, more frequent under 65 years, presence of HTA, dyslipidemia, diabetes, smoking, renal insufficiency, lung, heart, cancer and neurological disease. We did not find statistical differences in pregnant $(p=0.505)$, patient suffering cognitive $(p=0.484)$, liver $(p=0.1)$ or immune disease $(p=0.32)$ (Table 1). There were inverse relation (protective) between OGD and prone positioning
(0.005) and death $(<0.0001)$, but no with ICU admission $(0.165)$ or mechanical ventilation (0.292) (Table 3).

On multivariate logistic regression, OGD was found to be inversely related to death in COVID-19 patients. The odds ratio was $0.26(0.15-0.44)(p<0.001)$ and $Z$ was -5.05 (Table 3, Fig. 1). On the other hand, hypertension, renal insufficiency, autoimmune disease, oxygen saturation below $92 \%$ and age over 70 were independent risk factors for death.

\section{Discussion}

OGD has become an important symptom in COVID-19. It is a frequent symptom, affecting about $40 \%$ of outpatients and also an important infection and infective marker [3, 11, 12]. Although in our series, the prevalence of OGD was $8.5 \%$ (504 patients), this could be explained because inpatients use to be younger and have severe disease and it could be possible that anosmia is more frequent in mild disease [10]. In fact, in our study, this dysfunction was more frequent in younger patients $(<52$ years $15.80 \%$ vs $56-65$ y. $15.48 \%$ vs $66-76$ y. $7.05 \%$ vs $>76$ y. $3.47 p<0.000)$. Our results are in line with other inpatients studies [13]. Female were significantly more affected by these dysfunctions $(12.41 \%$ than male $8.67 \% p<0.0001)$. This finding is according to previous studies $[4,8,9]$. The olfactory and gustative dysfunction was significantly more frequent in Afro-Americans and Latino-American than Caucasian or Asian people $(p<0.0001)$. There were only 19 pregnant patients and we do not find any differences among them.

One interesting point is that anosmia was significantly more frequent in smokers $(27.85 \%$ vs $10.16 \% p<0.0001)$ and there was no relation with hypertension. These findings could be related to a previous lesion of nasal mucosa because the tobacco and predisposes to a higher olfactive epithelium lesion or the immune system has a higher reaction because of periodic toxic stimulation.

Patients reporting a loss of smell have fivefold decreased risk of death (OR $0.26 p>0.001)$ compare with those without this disorder, and it was not related to any other factor. These findings confirm previous studies, and it seems clear that the presence of anosmia would imply a more benign prognosis of the disease $[9,10]$. Indeed, the olfactory system is a unique neuroimmune interface where interaction between nervous and immune systems [14]. It is well known that virus or environmental toxicants can induce inflammatory responses, including infiltration of immune cells and production of cytokines [15, 16]. This inflammation can induce olfactive sensitive neurons degenerations and apoptosis as a protective mechanism [17]. Because the health of the central nervous system (CNS) is likely to be heavily influence by the immune status of the olfactory system, the reactions should be 
Table 1 Baseline demographics and clinical findings of COVID-19 individuals with or without olfactive and gustatory disfunction with hospital admission determined using multivariate analysis

\begin{tabular}{|c|c|c|c|c|c|}
\hline & \multicolumn{2}{|c|}{$N=5399$} & \multicolumn{2}{|c|}{ OGD } & $P$ \\
\hline \multicolumn{6}{|l|}{ Gender } \\
\hline Female & 2006 & $40.8 \%$ & 249 & $12.41 \%$ & \multirow[t]{2}{*}{0.0001} \\
\hline Male & 2906 & $59.2 \%$ & 252 & $8.67 \%$ & \\
\hline \multicolumn{6}{|l|}{ Age } \\
\hline 52 & 1190 & $24.7 \%$ & 188 & $15.80 \%$ & \multirow[t]{4}{*}{0.0001} \\
\hline $53-65$ & 1150 & $23.8 \%$ & 178 & $15.48 \%$ & \\
\hline $66-76$ & 1249 & $25.9 \%$ & 88 & $7.05 \%$ & \\
\hline$>76$ & 1238 & $25.6 \%$ & 43 & $3.47 \%$ & \\
\hline \multicolumn{6}{|l|}{ Ethnicity } \\
\hline Afro-American & 29 & $0.6 \%$ & 17 & $58.62 \%$ & \multirow[t]{5}{*}{0.0001} \\
\hline Caucasian & 4152 & $84.5 \%$ & 331 & $7.97 \%$ & \\
\hline Latino-American & 563 & $11.5 \%$ & 142 & $25.22 \%$ & \\
\hline Asian & 133 & $2.7 \%$ & 7 & $5.26 \%$ & \\
\hline Other & 35 & $0.7 \%$ & 4 & $11.43 \%$ & \\
\hline \multicolumn{6}{|l|}{ Pregnant } \\
\hline No & 4893 & $99.6 \%$ & 498 & $10.18 \%$ & \multirow[t]{2}{*}{0.505} \\
\hline Yes & 19 & $0.4 \%$ & 3 & $15.79 \%$ & \\
\hline \multicolumn{6}{|l|}{ HTA } \\
\hline No & 2475 & $50.5 \%$ & 287 & $11.60 \%$ & \multirow[t]{2}{*}{0.003} \\
\hline Yes & 2423 & $49.5 \%$ & 211 & $8.71 \%$ & \\
\hline \multicolumn{6}{|l|}{ Dyslipidemia } \\
\hline No & 3217 & $65.9 \%$ & 367 & $11.41 \%$ & \multirow[t]{2}{*}{0.0001} \\
\hline Yes & 1666 & $34.1 \%$ & 128 & $7.68 \%$ & \\
\hline \multicolumn{6}{|l|}{$\mathrm{DM}$} \\
\hline No & 3960 & $80.6 \%$ & 436 & $11.01 \%$ & \multirow[t]{2}{*}{0.0001} \\
\hline Yes & 952 & $19.4 \%$ & 65 & $6.83 \%$ & \\
\hline \multicolumn{6}{|l|}{ Smoking } \\
\hline Ex & 799 & $18 \%$ & 63 & $7.88 \%$ & \multirow[t]{3}{*}{0.0001} \\
\hline No & 3403 & $76.8 \%$ & 346 & $10.17 \%$ & \\
\hline Yes & 230 & $5.2 \%$ & 64 & $27.83 \%$ & \\
\hline \multicolumn{6}{|l|}{ Renal insufficiency } \\
\hline No & 4582 & $93.3 \%$ & 482 & $10.52 \%$ & \multirow[t]{2}{*}{0.012} \\
\hline Yes & 329 & $6.7 \%$ & 19 & $5.78 \%$ & \\
\hline Lung disease & & & & & \\
\hline No & 3965 & $80,7 \%$ & 428 & $10,79 \%$ & 0.010 \\
\hline Yes & 947 & $19.3 \%$ & 73 & $7.71 \%$ & \\
\hline Heart disease & & & & & \\
\hline 0 & 3721 & $76.4 \%$ & 405 & $10.88 \%$ & 0.011 \\
\hline 1 & 1148 & $23.6 \%$ & 92 & $8.01 \%$ & \\
\hline Neurological diseas & & & & & \\
\hline No & 4442 & $91.8 \%$ & 478 & $10.76 \%$ & 0.0001 \\
\hline Yes & 395 & $8.2 \%$ & 15 & $3.80 \%$ & \\
\hline Connective tissue $\mathrm{d}$ & & & & & \\
\hline No & 4713 & $97,3 \%$ & 477 & $10,12 \%$ & 0.484 \\
\hline Yes & 131 & $2.7 \%$ & 16 & $12.21 \%$ & \\
\hline Liver disease & & & & & \\
\hline No & 4645 & $96.1 \%$ & 482 & $10.38 \%$ & 0.1 \\
\hline Yes & 189 & $3.9 \%$ & 12 & $6.35 \%$ & \\
\hline Cancer & & & & & \\
\hline No & 4180 & $86.2 \%$ & 446 & $10.67 \%$ & 0.003 \\
\hline Yes & 667 & $13.8 \%$ & 44 & $6.60 \%$ & \\
\hline
\end{tabular}


Table 1 (continued)

\begin{tabular}{llllll}
\hline & $N=5399$ & OGD & $P$ \\
\hline Immune disease & & & & & \\
No & 4229 & $92.5 \%$ & 437 & $10.33 \%$ & 0.329 \\
Yes & 344 & $7.5 \%$ & 42 & $12.21 \%$ & \\
\hline
\end{tabular}

Table 2 Risk estimation in OGD vs no OGD patients
Table 3 Cox multivariate regression analysis regarding anosmia and other risk factors associated with in-hospital death

\begin{tabular}{lllllr}
\hline Variable & No OGD & OGD & OR & Interval & $P$ \\
\hline ICU admission & $303(6.02 \%)$ & $37(7.4 \%)$ & 1.213 & $0.851-1.729$ & 0.165 \\
Prone positioning & $495(10.40 \%)$ & $33(6.70 \%)$ & 0.626 & $0.434-0.902$ & 0.005 \\
Mechanical ventilation & $346(7.20 \%)$ & $39(8.00 \%)$ & 1.116 & $0.79-1.576$ & 0.292 \\
Death & $1079(22.00 \%)$ & $30(6.00 \%)$ & 0.226 & $0.155-0.329$ & $>0.0001$ \\
\hline
\end{tabular}

\begin{tabular}{llllll}
\hline Variable & OR & \multicolumn{2}{l}{$95 \%$ Confidence Interval } & $P$ & $Z$ \\
\hline Olfactive disorder & 0.26 & 0.15 & 0.44 & $<\mathbf{0 . 0 0 1}$ & -5.05 \\
Hypertension & 1.61 & 1.31 & 1.98 & $<\mathbf{0 . 0 0 1}$ & 4.51 \\
Obesity & 1.12 & 0.91 & 1.39 & 0.292 & 1.05 \\
Renal insufficiency & 3.58 & 2.61 & 4.89 & $<\mathbf{0 . 0 0 1}$ & 7.96 \\
Autoimmune disease & 2.43 & 1.76 & 3.34 & $<\mathbf{0 . 0 0 1}$ & 5.44 \\
Sat O2 <92\% & 5.72 & 4.71 & 6.95 & $<\mathbf{0 . 0 0 1}$ & 17.57 \\
Increase CRP & 1.86 & 1.20 & 2.89 & $\mathbf{0 . 0 0 6}$ & 2.77 \\
Age $>$ 70 years & 4.00 & 3.23 & 2.89 & $<\mathbf{0 . 0 0 1}$ & 4.94 \\
\hline
\end{tabular}

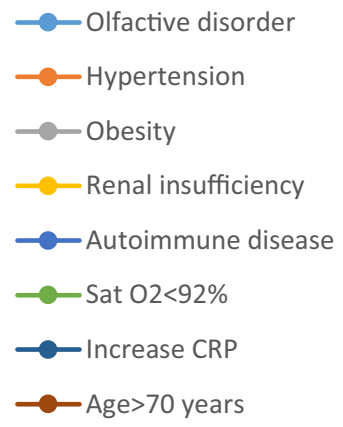

Odds Ratio

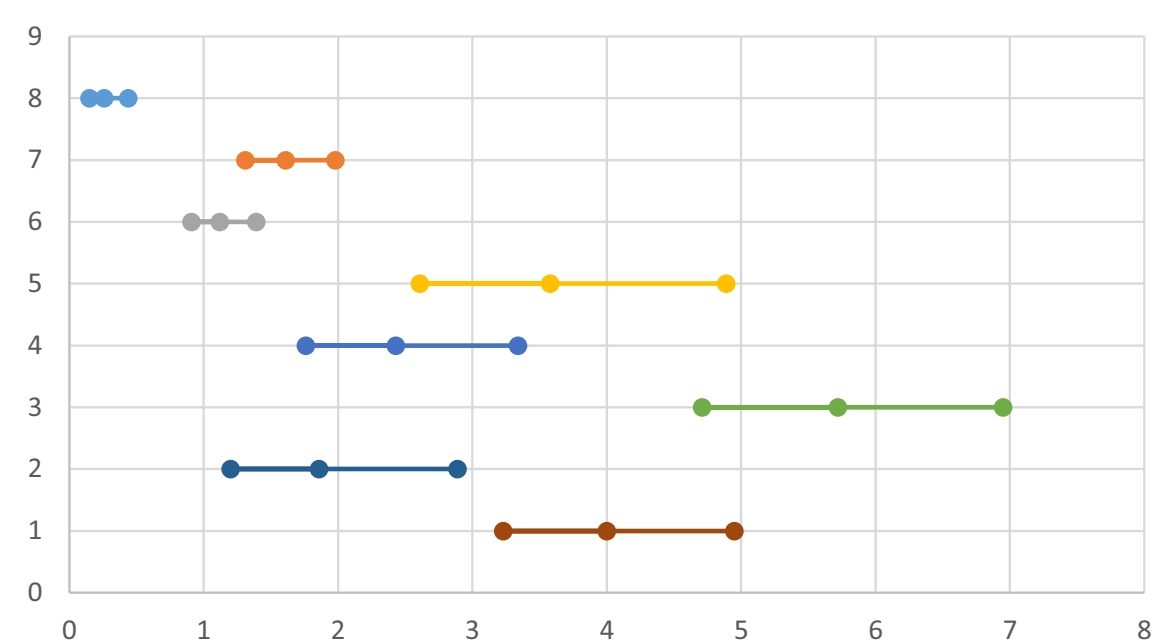

Fig. 1 Cox multivariate regression OR analysis regarding anosmia and other risk factors associated with in-hospital death. Y axis diseases, $\mathrm{X}$ axis odds ratio

harmonic, because new olfactory sensory neurons (OSN) may help in the repair of nasal damaged tissue [18]. On the other hand, immune cells in the olfactory mucosa regulate the depletion of old OSN and generation of new OSN [19]. This situation could explain our results that patients with an immune disfunction could have less OGD, because could be a lower immune reaction and therefore less epithelial and olfactive cells degeneration.

The pathophysiological point of view is quite interesting. Our group, like others, has already hypothesized about the possible relation between anosmia and CNS viral invasions [4, 20, 21]. In fact, the olfactory nerve is 
a traditional way because is excused to the external world $[22,23]$. Other viruses like poliovirus or influenza use this route [24]. And there is evidence that another coronavirus can reach the CNS direct through the olfactory bulb [25, 26]. Nevertheless, it has not been demonstrated the neurotropism of SARS-CoV-2, and the neurological symptoms seems to be more related to the cytokine storm than to direct invasion. Most of the cerebrospinal fluid (CSF) analysis has been negative for SARS-CoV-2 RCP, and our study shows a better prognosis something clearly different from those seen in other viruses like influenza [27]. For all those reasons, we agree that the anosmia have to be related to the invasion of the olfactive epithelium and the possibility of neuroinvasion has to be relatively low and could be more related with Neuropilin-1 [28, 29]. Furthermore, from the biological plausibility the olfactive sensitive neurons that do not express ACE2 receptor which is fundamental in the SARS-CoV-2 cell invasion [28-30]. Indeed, there is an elevated ACE2 expression in the olfactory neuroepithelium (230). Most of MRO studies shown normal olfactory bulb or an inflammation that could be related to both, cytokine liberation or neuronal invasion [7, 31, 32].

We believe that a prior nasal epithelium invasion by SARS-CoV-2 should activate normal immunological reactions in patients and promoted type 1 IF activating anti-viral immunity and suppression of hyperinflammation $[33,34]$. This means that infected cells are rapidly cleared, viruses are inactivated by neutralizing antibodies and there is minimal inflammation [34]. Avoiding in this way a dysfunctional immune response with excessive infiltration of monocytes, macrophages and T cells, the systemic cytokine storm and the secondary pulmonary and multiorgan damage [34].

The presence of anosmia is essential in the diagnosis of SARS-CoV-2 infection, but also could be important when in categorize patients and also in therapeutic decisionmaking. Even more, knowing that it is an early symptom of the disease. Knowing that other conditions as being Afro-American or Latino-American, Hypertension, renal insufficiency, or increase of RCP imply a worse prognosis we could develop a clinical score to estimate the vital prognosis for COVID-19 patients.

The exact pathogenesis of SARS-CoV-2 that causes olfactory and gustative disorders remains unknown but for sure is absolutely related to the prognosis. This point is relevant, insomuch as could be a plausible way to find a treatment. For this reason, study the anosmia and dysgeusia mechanism in COVID-19 seems to be fundamental. Further prospective studies are needed to confirm our results.

Supplementary Information The online version contains supplementary material available at https://doi.org/10.1007/s15010-021-01587-9.
Acknowledgements Cardiovascular Excellence SL, for their essential support in the database and HOPE webpage. All HOPE researchers.

Funding Unrestricted grant (Fundación Interhospitalaria para la Investigación cardiovascular, FIC. Madrid, Spain). This nonprofit institution had no role in the study design; collection, analysis, interpretation of data; in the writing of the report; nor in the decision to submit the paper for publication.

\section{Compliance with ethical standards}

Conflict of interest The authors declare that they no have no conflict of interest.

\section{References}

1. Margallo LN, Diaz M, Lim PP. 2019 Novel coronavirus pandemic: what do we know? Medicine. 2020;73:262-4.

2. Morrison AR, Johnson JM, Griebe KM, et al. Clinical characteristics and predictors of survival in adults with coronavirus disease 2019 receiving tocilizumab. J Autoimmun. 2020. https://doi. org/10.1016/j.jaut.2020.102512.

3. Beltrán-Corbellini Á, Chico-García JL, Martínez-Poles J, et al. Acute-onset smell and taste disorders in the context of COVID-19: a pilot multicentre polymerase chain reaction based case-control study. Eur J Neurol. 2020. https://doi.org/10.1111/ene.14273.

4. Gómez-Iglesias P, Porta-Etessam J, Montalvo T, et al. An online observational study of patients with olfactory and gustory alterations secondary to SARS-CoV-2 infection. Front Public Health. 2020;8:243. https://doi.org/10.3389/fpubh.2020.00243.

5. Kanwar D, Baig AM, Wasay M. Neurological manifestations of COVID-19. J Pak Med Assoc. 2020;70:S101-3. https://doi. org/10.5455/JPMA.20.

6. Cataldi M, Pignataro G, Taglialatela M. Neurobiology of coronaviruses: Potential relevance for COVID-19. Neurobiol Dis. 2020. https://doi.org/10.1016/j.nbd.2020.105007.

7. Aragão MFVV, Leal MC, Cartaxo Filho OQ, Fonseca TM, Valença MM. Anosmia in COVID-19 associated with injury to the olfactory bulbs evident on MRI. AJNR Am J Neuroradiol. 2020. https://doi.org/10.3174/ajnr.A6675.10.3174/ajnr.A6675.

8. Paniz-Mondolfi A, Bryce C, Grimes Z, et al. Central nervous system involvement by severe acute respiratory syndrome coronavirus-2 (SARS-CoV-2). J Med Virol. 2020;92:699-702. https://doi. org/10.1002/jmv.25915.

9. Yan CH, Faraji F, Prajapati DP, Ostrander BT, DeConde AS. Selfreported olfactory loss associates with outpatient clinical course in COVID-19. Int Forum Allergy Rhinol. 2020;10:821-31. https ://doi.org/10.1002/alr.22592.

10. Lechien JR, Chiesa-Estomba CM, De Siati DR, Horoi M, Le Bon SD, Rodriguez A, et al. Olfactory and gustatory dysfunctions as a clinical present2ation of mild-to-moderate forms of the coronavirus disease (COVID-19): a multicenter European study. Eur Arch Otorhinolaryngol. 2020. https://doi.org/10.1007/s0040 5-020-05965-1.

11. Klopfenstein T, Kadiane-Oussou NJ, Toko L, Royer PY, Lepiller Q, Gendrin V, Zayet S. Features of anosmia in COVID-19. Med Mal Infect. 2020. https://doi.org/10.1016/j.medmal.2020.04.006.

12. Menni C, Valdes AM, Freidin MB, et al. Real-time tracking of self-reported symptoms to predict potential COVID-19. Nat Med. 2020;26:1037-40. https://doi.org/10.1038/s41591-020-0916-2.

13. Mao L, Jin H, Wang M, et al. Neurologic manifestations of hospitalized patients with coronavirus disease 2019 in Wuhan, China. 
JAMA Neurol. 2020;77:683-90. https://doi.org/10.1001/jaman eurol.2020.1127.

14. Imamura F, Hasegawa-Ishii S. Environmental toxicants-induced immune responses in the olfactory mucosa. Front Immunol. 2016;7:475. https://doi.org/10.3389/fimmu.2016.00475.

15. Islam Z, Harkema JR, Pestka JJ. Satratoxin G from the black mold Stachybotrys chartarum evokes olfactory sensory neuron loss and inflammation in the murine nose and brain. Environ Health Perspect. 2006;114:1099-107. https://doi.org/10.1289/ehp.8854.

16. Kanaya K, Kondo K, Suzukawa K, Sakamoto T, Kikuta S, Okada $\mathrm{K}$, et al. Innate immune responses and neuroepithelial degeneration and regeneration in the mouse olfactory mucosa induced by intranasal administration of Poly(I:C). Cell Tissue Res. 2014;357:279-99. https://doi.org/10.1007/s00441-014-1848-2.

17. Sultan B, May LA, Lane AP. The role of TNF-alpha in inflammatory olfactory loss. Laryngoscope. 2011;121:2481-6. https://doi. org/10.1002/lary.22190.

18. Brann JH, Firestein SJ. A lifetime of neurogenesis in the olfactory system. Front Neurosci. 2014;26:182. https://doi.org/10.3389/ fnins.2014.00182.PMID:25018692;PMCID:PMC4071289.

19. Graziadei GA, Graziadei PP. Neurogenesis and neuron regeneration in the olfactory system of mammals. II. Degeneration and reconstitution of the olfactory sensory neurons after axotomy. J Neurocytol. 1979;8:197-213. https://doi.org/10.1007/BF011 75561.

20. Matías-Guiu J, Gomez-Pinedo U, Montero-Escribano P, GomezIglesias P, Porta-Etessam J, Matias-Guiu JA. Should we expect neurological symptoms in the SARS-CoV-2 epidemic? Es esperable que haya cuadros neurológicos por la pandemia por SARSCoV-2? Neurologia. 2020;35:170-5. https://doi.org/10.1016/j. nrl.2020.03.001.

21. Li YC, Bai WZ, Hashikawa T. The neuroinvasive potential of SARS-CoV2 may play a role in the respiratory failure of COVID19 patients. J Med Virol. 2020;92:552-5. https://doi.org/10.1002/ jmv.25728.

22. Kalinke U, Bechmann I, Detje CN. Host strategies against virus entry via the olfactory system. Virulence. 2011;2:367-70. https ://doi.org/10.4161/viru.2.4.16138.

23. Majde JA. Neuroinflammation resulting from covert brain invasion by common viruses - a potential role in local and global neurodegeneration. Med Hypotheses. 2010;75:204-13. https://doi. org/10.1016/j.mehy.2010.02.023.

24. Tesoriero C, Codita A, Zhang MD, et al. H1N1 influenza virus induces narcolepsy-like sleep disruption and targets sleepwake regulatory neurons in mice. Proc Natl Acad Sci U S A. 2016;113:E368-77. https://doi.org/10.1073/pnas.1521463112.
25. Wheeler DL, Athmer J, Meyerholz DK, Perlman S. Murine olfactory bulb interneurons survive infection with a neurotropic coronavirus. J Virol. 2017;91:e01099-e1117. https://doi.org/10.1128/ JVI.01099-17.

26. Youngentob SL, Schwob JE, Saha S, Manglapus G, Jubelt B. Functional consequences following infection of the olfactory system by intranasal infusion of the olfactory bulb line variant (OBLV) of mouse hepatitis strain JHM. Chem Senses. 2001;26:953-63. https://doi.org/10.1093/chemse/26.8.953.

27. Paterson RW, Brown RL, Benjamin L, et al. The emerging spectrum of COVID-19 neurology: clinical, radiological and laboratory findings. Brain. 2020. https://doi.org/10.1093/brain/awaa240.

28. Brann DH, Tsukahara T, Weinreb C, Logan DW, Datta SR. Non-neural expression of SARS-CoV-2 entry genes in the olfactory epithelium suggests mechanisms underlying anosmia in COVID-19 patients. BioRxiv. 2020. https://doi. org/10.1101/2020.03.25.009084.

29. Cantuti-Castelvetri L, Ojha R, Pedro LD, Djannatian M, Franz J, Kuivanen S, van der Meer F, Kallio K, Kaya T, Anastasina M, Smura T, Levanov L, Szirovicza L, Tobi A, Kallio-Kokko H, Österlund P, Joensuu M, Meunier FA, Butcher SJ, Winkler MS, Mollenhauer B, Helenius A, Gokce O, Teesalu T, Hepojoki J, Vapalahti O, Stadelmann C, Balistreri G, Simons M. Neuropilin-1 facilitates SARS-CoV-2 cell entry and infectivity. Science. 2020;370:856-60. https://doi.org/10.1126/science.abd2985.

30. Chen M, Shen W, Rowan NR, Kulaga H, Hillel A, Ramanathan M, Lane AP. Elevated ACE2 expression in the olfactory neuroepithelium: implications for anosmia and upper respiratory SARS-CoV-2 entry and replication. BioRxiv. 2020. https://doi. org/10.1101/2020.05.08.084996.

31. Galougahi MK, Ghorbani J, Bakhshayeshkaram M, Naeini AS, Haseli S. Olfactory bulb magnetic resonance imaging in SARS-CoV-2-induced anosmia: the first report. Acad Radiol. 2020;27:892-3. https://doi.org/10.1016/j.acra.2020.04.002.

32. Eliezer M, Hautefort C, Hamel AL, et al. Sudden and complete olfactory loss function as a possible symptom of COVID19. JAMA Otolaryngol Head Neck Surg. 2020. https://doi. org/10.1001/jamaoto.2020.0832.

33. Lin R, Mamane Y, Hiscott J. Multiple regulatory domains control IRF-7 activity in response to virus infection. J Biol Chem. 2000;275:34320-7. https://doi.org/10.1074/jbc.M002814200.

34. Tay MZ, Poh CM, Rénia L, MacAry PA, Ng LFP. The trinity of COVID-19: immunity, inflammation and intervention. Nat Rev Immunol. 2020;20:363-74. https://doi.org/10.1038/s4157 7-020-0311-8.

\section{Authors and Affiliations}

\section{Jesús Porta-Etessam ${ }^{1,23,24}$ (1) - Iván J. Núñez-Gil ${ }^{1}$. Nuria González García ${ }^{1,24}$. Cristina Fernandez-Perez ${ }^{2}$. María C. Viana-Llamas ${ }^{3} \cdot$ Charbel Maroun Eid $^{4} \cdot$ Rodolfo Romero $^{5} \cdot$ María Molina $^{6} \cdot$ Aitor Uribarri $^{7}$. Victor Manuel Becerra-Muñoz ${ }^{8} \cdot$ Marcos García Aguado $^{9}$. Jia Huang ${ }^{10}$ - Elisa Rondano ${ }^{11}$ - Enrico Cerrato ${ }^{12}$. Emilio Alfonso ${ }^{13}$. Alex Fernando Castro Mejía ${ }^{14}$. Francisco Marin ${ }^{15}$. Sergio Raposeiras Roubin ${ }^{16}$. Martino Pepe ${ }^{17}$. Gisela Feltes $^{18} \cdot$ Paloma Maté $^{19} \cdot$ Bernardo Cortese $^{20} \cdot$ Luis Buzón $^{21} \cdot$ Jorge Játiva Mendez ${ }^{22} \cdot$ Vicente Estrada $^{1}$}

1 Hospital Clínico San Carlos, Madrid, Spain

2 Instituto para la Mejora de la Asistencia Sanitaria, Madrid, Spain

3 Hospital Universitario Guadalajara, Guadalajara, Spain

4 Hospital Universitario La Paz. Instituto de Investigación Hospital Universitario La Paz (IdiPAZ), Madrid, Spain
5 Hospital Universitario Getafe, Madrid, Spain

6 Hospital Universitario Severo Ochoa, Leganés, Spain

7 Hospital Clínico Universitario de Valladolid, Valladolid, Spain

8 Hospital Clínico Universitario Virgen de La Victoria, Málaga, Spain 
9 Hospital Puerta de Hierro de Majadahonda, Madrid, Spain

10 The Second Affiliated Hospital of Southern, University of Science and Technology Shenzhen, Shenzhen, China

11 Sant'Andrea Hospital, Vercelli, Italy

12 San Luigi Gonzaga University Hospital, Orbassano and Rivoli Infermi Hospital, Rivoli, Turin, Italy

13 Institute of Cardiology and Cardiovascular Surgery, Havana, Cuba

14 Hospital General del Norte de Guayaquil IESS Los Ceibos, Guayaquil, Ecuador

15 Hospital Universitario Virgen de La Arrixaca, Murcia, Spain

16 Hospital Universitario Álvaro Cunqueiro, Vigo, Spain
17 Azienda Ospedaliero-Universitaria Consorziale Policlinico Di Bari, Bari, Italy

18 Hospital Nuestra Señora de América, Madrid, Spain

19 Hospital Universitario Infanta Sofia, San Sebastian de Los Reyes, Madrid, Spain

20 San Carlo Clinic, Milano, Italy

21 Hospital Universitario de Burgos, Burgos, Spain

22 Hospital de Especialidades de Las Fuerzas Armadas N1, Quito, Ecuador

23 Universidad Complutense de Madrid, Madrid, Spain

24 Neurology Department. C/Profesor Martín Lagos S/N, 28049 Madrid, Spain 